\title{
CORRESPONDENCE
}

\section{The maintenance of viability and spiral morphology of Helicobacter pylori in mineral water}

Helicobacter pylori, which colonises the human stomach, has been found to be a pathogen associated with several gastro-duodenal diseases such as gastritis, gastric ulcer, duodenal ulcer, gastric cancer [1] or gastric MALT lymphoma [2]. The mode of transmission of these organisms remains unknown. For the prevention of these $H$. pylori-associated diseases, it is necessary to elucidate the infectious routes of this organism. Water-borne infection by this organism has been reported in Peru [3]. It has also been reported that the organism retained viability in water [4]. However, ultrastructural investigations are required to determine whether or not $H$. pylori can maintain the membranous structures intact under osmotically unsuitable conditions such as in water. To clarify the viability, the morphology and the bacterial ultrastructure in water, $H$. pylori strain ATCC 43504 cultured in BBL liquid medium (Difco, Detroit, MI, USA) supplemented with horse serum 5\% on the first day, was stored in a commercial mineral water at $4^{\circ} \mathrm{C}$ for 7 days. The growth of the organism was then determined by plate count and the bacterial morphology and the ultrastructure were observed by scanning electron microscopy (SEM). The organism cultured in the liquid medium for 8 days under microaerobic conditions at $37^{\circ} \mathrm{C}$ was used as a control.

The viable counts of the organism cultured in liquid media were $2 \times 10^{8} \mathrm{cfu} / \mathrm{ml}$ at day 1 and $0 \mathrm{cfu} / \mathrm{ml}$ at day 8 , but those in mineral water were $1 \times 10^{10} \mathrm{cfu} / \mathrm{ml}$ after 7 days. This indicates that the organism can maintain viability even when stored in water for a week. SEM $(\times 10000)$ was used to determine the proportions of spiral and coccoid forms by counting 1000 bacteria. The proportions of spiral $H$. pylori cultured in liquid medium were $99.5 \%$ on day 1 and $0 \%$ on day 8 , respectively, but $95.0 \%$ after 7 days in mineral water. The experiments were performed three times and similar results were obtained on each occasion. This indicates that the organism can maintain its spiral form even when stored in water for a week at $4^{\circ} \mathrm{C}$. Fig. 1 shows the SEM image of spiral $H$. pylori in the liquid medium on the first day (a) and on the seventh day in mineral water (b).

The organism is known to have two morphological forms; a spiral form suitable for growth and a coccoid form, which is thought to take part in transmission, transformed from a spiral form under unsuitable conditions [5]. The organism is difficult to cultivate, need special conditions for growth and usually transforms into the coccoid form after 7 days in most liquid media. However, perhaps unexpectedly, most of the organisms retained spiral morphology under such adverse conditions as storage in mineral water for a week at $4^{\circ} \mathrm{C}$. Furthermore, it was observed that the
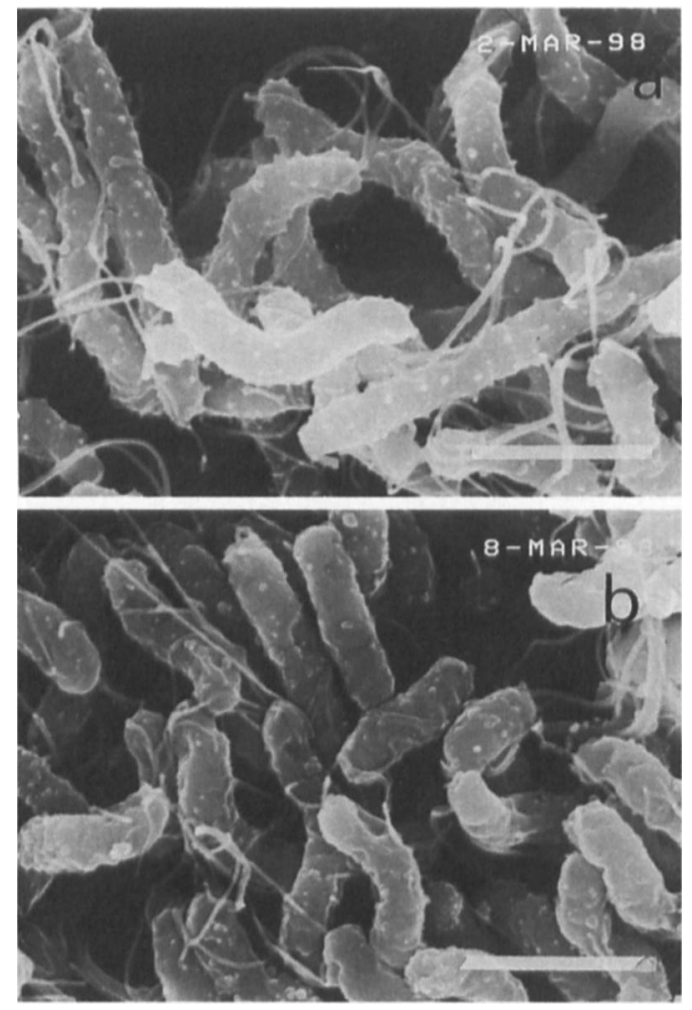

Fig. 1. SEM images of $H$. pylori (bar, $1.5 \mu \mathrm{m}$ ). (a) Spiral $H$. pylori in the liquid medium on the first day; (b) spiral $H$. pylori on the seventh day in mineral water.

organism stored in mineral water for 28 days was able to grow on agar medium (data not shown). From this study, it would appear that $H$. pylori can maintain viability in water from which it may directly colonise the stomach and proliferate as a spiral form.

Fujio Sato, Nagahito Saito, Eriko Shouji, Aziz Rani, Hiroshi Takeda, Toshiro Sugiyama and Masahiro Asaka, Third Department of Internal Medicine, Hokkaido University School of Medicine, Kita 15, Nishi 6, Kita-ku, Sapporo, Hokkaido, Japan.

\section{References}

1. Asaka M, Kimura $\mathrm{T}$, Kato $\mathrm{M}$ et al. Possible role of Helicobacter pylori infection in early gastric cancer development. Cancer 1994; 73: 2691-2694.

2. Wotherspoon AC, Ortiz-Hidalgo C, Falzon MR, Isaacson PG. Helicobacter pylori associated gastritis and primary B-cell gastric lymphoma. Lancet 1991; 338: 1175-1176.

3. Hulten $\mathrm{K}$, Han $\mathrm{SW}$, Enroth $\mathrm{H}$ et al. Helicobacter pylori in the drinking water in Peru. Gastroenterology 1996; 110: 1031-1035.

4. West AP, Millar MR, Thompkins DS. Survival of Helicobacter pylori in water and saline. J Clin Pathol 1990; 43: 609.

5. Bode G, Mauch F, Malfertheiner P. The coccoid forms of Helicobacter pylori. Criteria for their viability. Epidemiol Infect 1993; 111: 483-490. 